\title{
Persepsi dan Sikap Keluarga terhadap Perilaku Keluarga dalam Mencegah Penularan TB Paru
}

\author{
Suarnianti $^{1}$, Sri Angriani ${ }^{2 *}$ \\ 1. STIKES Nani Hasanuddin Makassar, Jl. P. Kemerdekaan VIII No. 24, Kota Makassar, Indonesia, 90245 \\ 2*. Poltekkes Kemenkes Makassar, Jl. Monumen Emmy Saelan III Tidung, Kota Makassar, Indonesia, 90222 \\ "e-mail: sriangrianisaleh@gmail.com
}

(Received: 03-10-2019; Reviewed: 26-12-2019; Accepted: 27-12-2019)

\begin{abstract}
Pulmonary tuberculosis (TB) is a contagious infectious disease caused by Mycobacterium tuberculosis which attacks the lungs and almost all other organs of the body. The five countries with the highest incidence of cases are Indonesia. The prevalence of tuberculosis is increasing every year. One of the causes is family perception and family attitude. The purpose of this study was to determine the effect of risk perceptions and family attitudes on family behavior in preventing pulmonary TB transmission at the Bara Baraya Public Health Center in Makassar. This research is descriptive-analytic research with cross-sectional study design. The population in this study was the family of 41 patients suffering from pulmonary TB at the Bara Baraya Public Health Center in Makassar. Sampling using Purposive Sampling, which is where the sample used is only 37 people. Data collection is done using observation sheets, questionnaires, Microsoft Excel programs and Statistics programs (SPSS). Data analysis includes univariate analysis by looking for frequency distribution, bivariate analysis with Chi-Square statistical test $(\alpha=0.05)$ with Continuity Correction to determine the effect between variables. The results of the bivariate analysis found risk perception influences family behavior in preventing pulmonary $T B$ transmission $(\rho=0.004)$ and family attitude influences family behavior in preventing pulmonary TB transmission $(\rho=0.004)$. The conclusion in this study is that there is an influence between risk perception and family attitudes on family behavior in preventing pulmonary TB transmission.
\end{abstract}

Keywords : Family Attitudes, Perception, Pulmonary Tuberculosis (TB)

\begin{abstract}
Abstrak
Tuberkulosis (TB) paru merupakan penyakit infeksi menular yang disebabkan Mycobacterium tuberculosis yang menyerang paru-paru dan hampir seluruh organ tubuh lainnya. Lima negara dengan insiden kasus tertinggi adalah Indonesia. Prevelensi kejadian tuberkulosis ini terus meningkat tiap tahunnya. Salah satu penyebabnya adalah persepsi keluarga dan sikap keluarga. Tujuan penelitian ini adalah untuk mengetahui pengaruh persepsi berisiko dan sikap keluarga terhadap perilaku keluarga dalam mencegah penularan TB paru di Puskesmas Bara Baraya Makassar. Penelitian ini merupakan jenis penelitian Deskriptif Analitik dengan desain/rancangan Cross Sectional Study. Populasi dalam penelitian ini adalah keluarga dari 41 pasien yang menderita TB paru di Puskesmas Bara Baraya Makassar. Pengambilan sampel menggunakan Purposive Sampling yaitu dimana sampel yang di gunakan hanya 37 orang. Pengumpulan data dilakukan dengan menggunakan lembar observasi, kuesioner, program Microsoft Excel dan program Statistic (SPSS). Analisis data mencakup analisis univariat dengan mencari distribusi frekuensi, analisis bivariat dengan uji stastistik Chi Square $(\alpha=0.05)$ dengan korelasi Continuity Correction untuk mengetahui pengaruh antar variabel. Hasil analisis bivariat didapatkan persepsi berisiko mempengaruhi perilaku keluarga dalam mencegah penularan TB paru $(\rho=0.004)$ dan sikap keluarga mempengaruhi perilaku keluarga dalam mencegah penularan TB paru $(\rho=0.004)$. Kesimpulan dalam penelitian ini adalah ada pengaruh antara persepsi berisiko dan sikap keluarga terhadap perilaku keluarga dalam mencegah penularan TB paru.
\end{abstract}

Kata Kunci : Persepsi, Sikap Keluarga, Tuberkulosis (TB) Paru 


\section{Pendahuluan}

Tuberkulosis (TB) merupakan penyakit yang menjadi perhatian global. Tuberkulosis diperkirakan masih menyerang 9.6 juta orang dan menyebabkan 1.2 juta kematian pada tahun 2014. India, Indonesia dan China merupakan negara dengan penderita TB terbanyak yaitu berturut-turut $23 \%, 10 \%$ dan $10 \%$ dari seluruh penderita di dunia (WHO, 2015). Indonesia berada di posisi ke empat terbesar dunia dalam jumlah penderita TB, setelah China dan Pakistan. Angka temuan kasus baru (Case Detection Rate/CDR) tahun 2008 di Indonesia sebesar 72.8 per 100 penduduk atau didapati 166.376 penderita baru dengan Basil Tahan Asam(BTA) positif. Angka kesembuhannya adalah (Success Rate/SR) sebesar 89 per 100 penduduk (89\%). Hal tersebut melampaui target global, yaitu CDR 7 per 100 penduduk dan SR 85\%. Kasus TB paru BTA positif baru tahun 2009 sebanyak 169.213 kasus dan pada tahun 2010 sebanyak 183.366 kasus (Masriadi, 2017).

Hasil laporan Riskesdas tahun 2007 TB paru klinis dengan prevalensi 1,03\% enam dari tiga kabupaten/kota di atas angka Provinsi dan tertinggi di Kabupaten Tana Toraja (6.8\%). Prevalensi TB paru cenderung meningkat sesuai bertambahnya umur, tertinggi pada tahun 65 tahun. Menurut jenis kelamin, tertinggi pada laki-laki dibandingkan perempuan. Hampir tiga kali lebih tinggi di pedesaan dibandingkan dengan perkotaan.Tingkat pendididkan terendah lima kali lebih tinggi dari pada pendidikan tinggi (Dinas Kesehatan, 2017). Tuberkulosis paru dapat dicegah. Beberapa cara untuk membantu mencegah penularan TB agar infeksi bakteri tidak menular kepada orang-orang di sekitar penderita baik itu teman atau pun keluarga; memisahkan makanan dengan pasien TB paru, menjalankan hidup sehat, mengurangi kontak dengan penderita, menghindari penularan melalui dahak pasien, dan tidak tidur sekamar dengan orang yang menderita TB meskipun keluarga sendiri sebagai usaha pencegahan TB agar tidak terinfeksi.

Tuberkulosis paru merupakan penyakit yang berat. Bila salah satu atau beberapa anggota keluarga menderita TB paru, akan berpengaruh terhadap anggota keluarga lainnya yang ada di sekitarnya. Dalam penanganan penyakit seperti ini keluarga mempunyai peranan yang sangat penting dalam proses penyembuhan penyakit. Anggota keluarga akan memberikan informasi mengenai penyakit, memberikan dukungan, dan mencegah penularan penyakit tersebut (Wahyuni \& Agustina, 2017).

Persepsi keluarga terhadap penyakit TB berdampak pada upaya mereka untuk mencegah penularan TB paru. Persepsi merupakan kemampuan otak untuk menerjemahkan stimulus yang masuk kedalam alat indra manusia. Ada yang mempersepsikan sesuatu itu baik atau positif maupun negatif yang akan memengaruhi tindakan manusia yang tampak nyata. Persepsi merupakan proses diterimanya rangsangan melalui pancaindra diikuti oleh perhatian sehingga individu mampu mengetahui, mengartikan, dan menghayati tentang hal yang diamati. Oleh karena itu pengindraan individual akanmengaitkannya dengan stimulus, sedangakan dengan persepsi, orang akan mengaitkan dengan objek. Dengan persepsi individu akan menyadari tentang keadaan disekitarnya dan juga keadaan dirinya sendiri.

Berdasarkan data yang didapatkan di Puskesmas Bara-baraya di laporkan bahwa jumlah penderita TB tahun 2016 mencapai 129 sedangkan pada tahun 2017 mencapai 144 dan tahun 2018 dari bulan Januari sampai Maret mencapai 41 kasus. Sehingga dapat dilihat dari tahun 2016 sampai 2017 bahwa pasien dengan kasus TB mengalami peningkatan. Berdasarkan uraian dari latar belakang di atas perumusan masalah dari penelitian ini adalah "Apakah ada pengaruh persepsi beresik dan sikap keluarga terhadap perilaku keluarga dalam mencegah penularan TB di Puskesmas Bara-baraya".

\section{Metode}

Jenis penelitian yang digunakan dalam penelitian ini adalah penelitian deskriptif analitik dengan desain/rancangan Cross Sectional Study adalah penelitian yang menekankan waktu pengukuran/observasi data variabel independen dan dependen hanya satu kali pada satu saat (Nursalam, 2016). Penelitian dilakukan di Puskesmas Bara-baraya Makassar mulai dari 22 Februari - 6 Maret 2019. Populasi dalam penelitian ini adalah keluarga dari 41 pasien yang mengalami TB paru di Puskesmas Bara-baraya Makassar. Teknik sampling yang digunakan yaitu purposive sampling yaitu menetapkan sampel dengan cara memilih sampel berdasarkan kriteria yang telah ditentukan sehingga diperoleh jumlah sampel sebanyak 37 orang.

Adapun kriteria yang ditentukan untuk pemilihan sampel antara lain : (a) merupakan keluarga yang memiliki pasien TB paru yang berobat ke Puskesmas Bara-baraya Makassar, (b) keluarga yang menyetujui mengisi informed consent. Pengumpulan data diperoleh dari dua tahap yaitu dari data primer yang merupakan hasil dari penelitian yang dilakukan dan data sekunder yang terbagi atas dua yaitu internal yang berasal dari data medical research dan eksternal yang berasal dari data hasil publikasi, instansi pemerintah, badan ilmiah dan lainnya. Pengumpulan data ini dilakukan dengan menggunakan lembar observasi dan kuesioner. Analisis data yang dilakukan mencakup analisis univariat yaitu dengan mencari distribusi frekuensi dan analisis bivariat dengan menggunakan uji statistic Chi-Square $(\alpha=0,05)$ dengan korelasi Continuity Correction untuk mengetahui pengaruh antar variabel. 


\section{Hasil}

1. Analisis univariat

a. Jenis Kelamin

Tabel 1. Distribusi frekuensi karakteristik responden berdasarkan jenis kelamin di puskesmas bara baraya makassar tahun 2019

\begin{tabular}{ccc}
\hline Jenis Kelamin & n & \% \\
\hline Laki-laki & 15 & 40,5 \\
Perempuan & 22 & 59,5 \\
\hline Jumlah & 37 & 100 \\
\hline
\end{tabular}

Tabel 1. menunjukkan bahwa diketahui jumlah responden penelitian terbanyak dengan jenis kelamin perempuan yaitu sebanyak 22 responden (59.5\%) dan laki-laki sebanyak 15 responden (40,5\%).

b. Umur

Tabel 2. Distribusi frekuensi karakteristik responden berdasarkan umur di puskesmas bara baraya makassar tahun 2019

\begin{tabular}{ccc}
\hline Umur & n & \% \\
\hline 25-30 Tahun & 14 & 37,8 \\
31-35 Tahun & 19 & 51,4 \\
36-40 Tahun & 4 & 10,8 \\
\hline Jumlah & 37 & 100 \\
\hline
\end{tabular}

Tabel 2. menunjukkan bahwa diketahui jumlah responden kategori umur 25-30 tahun sebanyak 14 responden $(37,8 \%), 31-35$ tahun sebanyak 19 responden (51.4\%), dan 36-40 tahun sebanyak 4 responden $(10,8 \%)$.

c. Agama

Tabel 3. Distribusi frekuensi karakteristik responden berdasarkan agama di puskesmas bara baraya makassar tahun 2019

\begin{tabular}{ccc}
\hline Agama & n & \% \\
\hline Islam & 33 & 89,2 \\
Kristen & 4 & 10,8 \\
\hline Jumlah & 37 & 100 \\
\hline
\end{tabular}

Tabel 3. menunjukkan bahwa jumlah responden kategori agama Islam sebanyak 33 responden $(89,2$ $\%)$ dan kristen sebanyak 4 responden $(10,8 \%)$.

d. Status

Tabel 4. Distribusi frekuensi karakteristik responden berdasarkan status di puskesmas bara baraya makassar tahun 2019

\begin{tabular}{ccc}
\hline Status & n & \% \\
\hline Kawin & 23 & 62,2 \\
Belum Kawin & 14 & 35,8 \\
\hline Jumlah & 37 & 100 \\
\hline
\end{tabular}

Tabel 4. menunjukkan bahwa jumlah responden kategori status pernikahan yaitu kawin sebanyak 23 responden $(62,2 \%)$ dan belum kawin sebanyak 14 responden $(35,8 \%)$.

e. Persepsi Keluarga Pasien

Tabel 5. Distribusi frekuensi responden berdasarkan persepsi keluarga pasien di puskesmas barabaraya makassar tahun 2019

\begin{tabular}{ccc}
\hline Persepsi Keluarga & n & Persentase (\%) \\
\hline Negatif & 27 & 73.0 \\
Positif & 10 & 27.0 \\
\hline
\end{tabular}

Tabel 5. menunjukkan bahwa jumlah responden terbanyak dengan kategori persepsi negatif 27 responden $(73.0 \%)$ dan terendah pada persepsi positif 10 responden $(27.0 \%)$. 
f. Sikap Keluarga Pasien

Tabel 6. Distribusi frekuensi responden berdasarkan sikap keluarga pasien di puskesmas barabaraya makassar tahun 2019

\begin{tabular}{ccc}
\hline Sikap Keluarga & n & Persentase (\%) \\
\hline Baik & 11 & 29.7 \\
Kurang & 26 & 70.3 \\
\hline
\end{tabular}

Tabel 6. Menunjukkan bahwa jumlah responden terbanyak dengan kategori tidak baik 26 responden (70.3\%) dan terendah pada sikap tidak baik 11 responden $(29.7 \%)$.

g. Pencegahan Tuberkolosis Paru (TB Paru)

Tabel 7. Distribusi frekuensi responden berdasarkan pencegahan tuberkulosis paru (tb paru) di puskesmas bara-baraya makassar tahun 2019

\begin{tabular}{ccc}
\hline $\begin{array}{c}\text { Perilaku Pencegahan } \\
\text { Tuberkulosis Paru (TB } \\
\text { Paru) }\end{array}$ & n & Persentase (\%) \\
\hline Baik & & \\
Tidak & 11 & 29.7 \\
\hline
\end{tabular}

Tabel 7. menunjukkan bahwa jumlah responden terbanyak dengan kategori pencegahan TB paru yang baik 27 responden (73.0\%) dan terendah pada pencegahan kurang baik 10 responden (27.0\%).

2. Analisis Bivariat

a. Pengaruh Antara Persepsi Keluarga terhadap Perilaku Keluarga dalam Mencegah Penularan TB Paru

Tabel 8. Pengaruh antara persepsi keluarga terhadap perilaku keluarga dalam mencegah penularan tb paru di puskesmas bara-baraya makassar tahun 2019

\begin{tabular}{ccccccccc}
\hline & \multicolumn{3}{c}{$\begin{array}{c}\text { Perilaku Pencegahan TB } \\
\text { Persepsi Berisiko } \\
\text { Keluarga }\end{array}$} & \multicolumn{9}{c}{ Total } & \multirow{2}{*}{$\boldsymbol{\rho}$} \\
\cline { 2 - 9 } & \multicolumn{2}{c}{ Baik } & \multicolumn{1}{c}{ Kurang } & & \\
\cline { 2 - 9 } & $\mathbf{n}$ & $\boldsymbol{\%}$ & $\mathbf{n}$ & $\boldsymbol{\%}$ & $\mathbf{n}$ & $\%$ & \\
\hline Positif & 7 & 70.0 & 3 & 30.0 & 10 & 100.0 & \multirow{2}{*}{0.004} \\
Negatif & 4 & 14.8 & 23 & 85.2 & 27 & 100.0 & \\
\hline
\end{tabular}

Berdasarkan tabel 8. data di atas terlihat bahwa dari 37 responden terdapat 10 responden (100\%) yang mempunyai persepsi positif dengan rincian responden yang menjawab baik sebanyak 7 responden (70.0\%) dan yang menjawab kurang sebanyak 3 responden (30.0\%). Sedangkan dari 27 responden $(100 \%)$ yang mempunyai persepsi negatif dengan rincian responden yang menjawab baik sebanyak 4 responden $(29.7 \%)$ dan yang menjawab tidak sebanyak 23 responden $(85.2 \%)$. Berdasarkan hasil uji statistic chi-square dengan korelasi Continuity Correction diperoleh nilai $\rho=0.004<\alpha(0,05)$, sehingga H0 di tolak dan Ha diterima. Jadi, ada pengaruh antara persepsi berisiko terhadap perilaku keluarga dalam mencegah penularan TB paru.

b. Pengaruh Antara Sikap Keluarga terhadap Perilaku Keluarga dalam Mencegah Penularan TB Paru Tabel 9. Pengaruh antara sikap keluarga terhadap perilaku keluarga dalam mencegah penularan tb paru di puskesmas bara-baraya makassar tahun 2019

\begin{tabular}{ccccccccc}
\hline & \multicolumn{3}{c}{$\begin{array}{c}\text { Perilaku Pencegahan TB } \\
\text { Persepsi Berisiko } \\
\text { Keluarga }\end{array}$} & \multicolumn{9}{c}{ Total } & \multirow{2}{*}{$\boldsymbol{\rho}$} \\
\cline { 2 - 9 } & \multicolumn{2}{c}{ Baik } & Kurang & & \\
\cline { 2 - 9 } & $\mathbf{n}$ & $\boldsymbol{\%}$ & $\mathbf{n}$ & $\boldsymbol{\%}$ & $\mathbf{n}$ & $\%$ & \\
\hline Baik & 7 & 70.0 & 3 & 30.0 & 10 & 100.0 & \multirow{2}{*}{0.004} \\
Kurang & 4 & 14.8 & 23 & 85.2 & 27 & 100.0 & \\
\hline
\end{tabular}

Berdasarkan tabel 9. data di atas terlihat bahwa dari 37 responden terdapat 10 responden (100\%) yang mempunyai sikap baik dengan rincian responden yang menjawab baik sebanyak 7 responden 
(70.0\%) dan yang menjawab kurang sebanyak 3 responden (30.0\%). Sedangkan dari 27 responden (100\%) yang mempunyai sikap kurang dengan rincian responden yang menjawab baik sebanyak 4 responden $(29.7 \%)$ dan yang menjawab tidak sebanyak 23 responden (85.2\%). Berdasarkan hasil uji statistic chi-square dengan korelasi Continuity Correction diperoleh nilai $\rho=0,004<\alpha(0,05)$, sehingga H0 di tolak dan Ha diterima. Jadi, ada pengaruh antara sikap keluarga terhadap perilaku keluarga dalam mencegah penularan TB paru.

\section{Pembahasan}

Pengaruh Persepsi Berisiko Terhadap Perilaku Keluarga dalam Mencegah Penularan TB Paru menunjukkan bahwa hasil uji statistik Chi-square dengan korelasi Continuity Correction diperoleh nilai $\rho=0,004<\alpha(0,05)$. Jadi dapat dikatakan bahwa ada pengaruh antara persepsi berisiko terhadap perilaku keluarga dalam mencegah penularan TB paru. Persepsi dalam arti sempit adalah penglihatan, bagaimana seseorang melihat sesuatu. Dalam arti luas, persepsi adalah bagaimana seseorang memandang atau mengartikan sesuatu (Donsu, 2017). Sejalan dengan yang dikemukakan oleh Wahyuni (2015) yang membahas tentang kajian persepsi, pengetahuan terhadap pencegahan penularan penyakit TB di Puskesmas, bahwa persepsi dapat diartikan sebagai proses penilaian seseorang terhadap objek tertentu yang dapat kita tangkap melalui indra, dimana pengindraan orang akan mengartikan dengan stimulus, sedangkan dalam persepsi orang akan mengaitkan dengan objek yang dituju.persepsi adalah proses akhir dari pengamatan yang diawali oleh proses pengindraan yaitu diterimannya stimulus oleh alat indra kemudian individu menyadari tentang sesuatu yang dinamakan persepsi.

Sugiarto (2018) mengemukakan bahwa rendahnya persepsi terhadap pencegahan TB paru dikarenakan persepsi seseorang hadir disaat tertentu, semakin besar manfaat yang terkait maka semakin besar dengan perubahan yang menguntungkan, sebaliknya semakin kecil manfaat yang terkait maka semakin kecil pula peruahan yang menguntungkan. Persepsi seseorang mempengaruhi perubahan perilaku yang akan dilakukan dengan melihat atau mengetahui tentang sesuatu yang didapatkan. Menurut Mbuthia (2018) menyatakan bahwa banyaknya kesalahan persepsi pasien, keluarga dan masyarakat dikarenakan Pengetahuan dan informasi yang salah tentang peyebab dan cara penularan tuberkulosis paru. Salah satu kesalah pahaman persepsi tentang tuberkulosis dimana banyak kepercayaan dan mitos yang menganggap bahwa santet sebagai penyebab dari dari tuberkulosis. Kesalahpahaman ini cenderung memberikan informasi yang salah kepada keluarga atau masyarakat tentang control dan tindakan pencegahan yang harus mereka lakukan.

Kigozi (2017) mengungkapkan bahwa, ssebagian besar model perubahan perilaku menyatakan bahwa persepsi berisiko adalah prasyarat untuk perubahan perilaku. Persepsi yang positif dimana mereka percaya bahwa berpotensi berisiko terinfeksi tuberkulosis paru. Dimana dapat memberikan kesempatan untuk fokus pada cara agar dapat mengurangi risiko infeksi melalui diagnosis dan pengobatan dini. Hal ini secara signifikan dapat menurangi penyebaran tuberkulosis paru lebih lanjut. Hasil ini sejalan dengan penelitian Wahyuningsih (2015) yang membahas tentang hubungan persepsi penderita TB paru tentang pencegahan penularan dengan upaya pencegahan penularan TB paru. Dari 22 responden sebagian besar responden memiliki persepsi negative yaitu 12 responden $(54.5 \%)$. Sedangkan responden yang melakukan pencegahan TB paru dengan kurang baik yaitu sebanyak 15 responden (68.2\%). Menurut asumsi peneliti persepsi seseorang sangat mempengaruhi tindakan yang akan dilakukannya. Semakin positif persepsi yang dimiliki seseorang maka semakin baik pula upaya pencegahan penularan yang dilakukan, begitupun sebaliknya. Sehingga disarankan kepada keluarga untuk lebih memberikan dukungan atau motivasi kepada penderita agar lebih meninggkatkan upaya untuk kesembuhannya.

Pengaruh sikap keluarga terhadap perilaku keluarga dalam mencegah penularan TB paru menunjukkan hasil uji statistik Chi-square dengan korelasi Continuty Correction diperoleh nilai $\rho=0.004<\alpha(\alpha=0.05)$. Jadi dapat dikatakan bahwa ada pengaruh antara sikap keluarga terhadap perilaku keluarga dalam mencegah penularan TB paru. Berdasarkan hasil penelitian yang telah dilakukan bahwa 7 responden $(70.0 \%)$ yang memiliki sikap keluarga yang baik dengan perilaku pencegahan TB paru yang baik di karenakan keluarga memahami cara pencegahan TB paru, dan 3 responden $(30.0 \%)$ memiliki sikap keluarga yang baik dengan pencegahan TB paru yang kurang di karenakan keluarga tidak mengusahakan sinar matahari dapat masuk kedalam rumah nya. Sedangakan 4 responden (14.8\%) yang memiliki sikap keluarga yang kurang dengan perilaku pencegahan TB paru baik di karenakan keluarga tidak memberikan perlakuan berbeda kepada salah satu keluarga yang meingidap penyakit TB paru, dan sikap keluarga yang kurang dengan perilaku pencegahan TB paru yang kurang di karenakan keluarga pasien tidak segera membawa penderita ke pelayanan kesehatan pada saat penderita mengalami batuk-batuk.

Rizana (2016) mengemukakan bahwa sebagian besar keluarga tidak mengetahui cara penularan dan tindakan pencegahan TB paru seperti tidak menutup mulut saat bersin dan batuk, meludah disembarang tempat, tidak mengetahui sikap yang benar dalam pencegahan TB paru seperti cahaya matahari harus masuk kedalam rumah dan tidak menunjukan perilaku yang tepat dalam mencegah penularan TB paru seperti memisahkan makanan untuk penderita TB paru dengan anggota keluarga lainnya. Menurut Boron dan Bryne (2003 dalam Donsu, 
2017) sikap merupakan evaluasi terhadap berbagai aspek dalam dunia sosial. Para peneliti psikologi sosial menempatkan sikap sebagai hal yang penting dalam interaksi sosial. Karena sikap dapat memengaruhi banyak hal tentang perilaku. Bahkan para peneliti psikologi sosial menempatkan sikap sebagai isu sentral yang dapat memengaruhi perilaku seseorang. Penelitian Freitas (2015) mengungkapkan bahwa masih banyak keluarga yang bersikap menghindar berbincang tentang TB paru dihadapan teman atau orang lain. Karena merasa mempermalukan diri mereka. Sehingga menunjukan bahwa sikap diskriminatif karna TB memiliki pengaruh besar di cakrawala klinis penyakit ini, karna akan berdampak buruk bagi psikologis penderita dalam proses penyembuhan.

Nyusulu (2018) mengemukakan bahwa sikap dan peran keluarga sangat mempengaruhi dalam proses penyembuhan. Berdasarkan hal tersebut, memberdayakan penderita dengan informasi yang tepat dan benar serta menimbulkan sikap positif terhadap penderita untuk kesembuhannya sangat penting untuk pengendalian penyakit yang efektif. Menurut Yermi (2018) sikap keluarga sanggat penting dalam pencegahan TB paru. Deteksi dan pengobatan dini adalah penentu penting keberhasilan pengendalian TB paru. Keluarga atau pasien harus lebih berpartisipasi dalam kegiatan pendidikan kesehatan agar dapat meningkatkan perilaku pencegahan TB paru. Hal ini sejalan dengan penelitian Masdalimah (2018), yang membahas tentang penngetahuan, sikap dan tindakan penderita TBC paru terhdap upaya pencegahan penularan pentakit TB paru $(\rho=0.002)$. Dari 56 orang $(87.5 \%)$ responden terdapat 13 orang $(23.2 \%)$ melakukan tindakan pencegahan penularan TB paru yang baik dan 43 orang $(76.8 \%)$ memiliki tindakan buruk terhadap pencegahan TB paru paru di Kecamatan Padangsipuan Tenggara Kota Padangsipuang. Sikap reponden yang tinggi terhadap upaya pencegahan penularan TB paru yaitu kemauan mencari pelyanan kesehatan yang didukung dengan kemauan untuk berperilaku hidup sehat.

Menurut asumsi peneliti bahwa sikap sangat mempengaruhi perilaku seseorang. Karena semakin baik sikap seseorang maka semakin baik pula upaya perilaku pencegahan penularan yang dilakukan, begitupun sebaliknya. Sehingga disarankan kepada keluarga agar lebih memperhatikan PHBS nya, memperhatikan lingkungan nya seperti memperhatikan ventilasi rumah agar sinar matahari dapat masuk dan lebih mengetahui tanda dan gejala TB paru sehingga segera memeriksakan diri ke pelayanan kesehatan.

\section{Kesimpulan}

Berdasarkan hasil penelitian tentang pengaruh persepsi berisiko dan sikap keluarga terhadap perilaku keluarga dalam mencegah penularan Tuberklosis paru (TB paru) di Puskesmas Bara Baraya Makassar yang di laksanakan mulai dari tanggal 23 Januari sampai 6 Februari tahun 2019 dengan jumlah responden 37 orang dapat disimpulkan bahwa, ada pengaruh antara persepsi berisiko dan sikap keluarga terhadap perilaku keluarga dalam mencegah penularan TB paru.

\section{Saran}

Diharapkan adanya peran keluarga dalam membantu pencegahan penularan TB paru dengan adanya dukungan dari pengetahuan, persepsi dan sikap keluarga itu sendiri dalam berperilaku.

\section{Referensi}

Dinas Kesehatan, P. 2017. Profil Kesehatan Provinsi Sulawesi Selata 2016

Donsu, J. D. T. 2017. Psikologi Keperawatan. Yogyakarta: Pustaka Baru Press

Freitas, I. M. D. 2015. Factors Associated With Knowledge About Tuberculosis And Attitudes Of Relatives Of Patients With The Disease . Brazil. Rev. bras. Epidemiol.

Kigozi, N. G. 2017. Tuberculosis Knowledge, Attitudes and Practices Of Patients at Primary Health Care Facilities In a South African Metropolitan: Research Towords Improved Health Education. BMC Public Health

Masriadi. 2017. Epidemologi Penyakit Menular. Depok: Rajawali pers

Mbuthia, G. W. 2018. Knowledge and Perceptions Of Tuberculosis Among Patients In a Pastoralist Comumunity In Kenya: a Qualitative Study. African Medical Journal 
Musdalimah.B. 2018. Pengetahuan Sikap Dan Tindakan Penderita TBC Paru Terhadap Upaya Pencegahan Penularan Penyakit TB Paru Di Kecamatan Pandangsipuan Tenggara. Padangsipuang

Nursalam. 2016. Metode Penelitian Ilmu Keperawatan (Edisi 4). Jakarta: Salemba Medika

Nyusulu, P. 2018. Knowledge, Beliefs and Perceptions Of Tuberculosis Among Community Members In Ntcheu District Malawi. South African: Journal Of Multidisciplinary Healthycare

Rizana. 2016. Pengetahuan, Sikap Dan Perilaku Keluarga Dalam Mencegah Penularan Tuberkulosis Paru. Jurnal Ilmu Keperawatan

Sugiarto. 2018. Pengetahuan, Persepsi, self efficary dan pengaruh Interpersonal Penderita Terhadap Pencegahan Penularan TB Paru (Descriptif Study). Journal Of Public Health

Wahyuni, C.U, \& Agustina, S. 2017. Pengetahuan Tindakan Pencegahan Penularan Penyakit Tuberkulosa Paru Pada Keluarga Kontak Serumah. Jurnal Berkala Epidemologi.

Wahyuningsih, B.D. 2015. Hubungan Persepsi Penderita TB Paru Tentang Pencegahan Penularan Dengan Upaya Pencegahan Penularan TB Paru. Mojokerto

Wahyuni. 2015. Kajian Persepsi, Pengetahuan Terhadap Pencegahan Penularan Penyakit TB DI Puskesmas. Jurnal PROFESI

WHO. 2015. Global Tuberculosis Report. Geneva: World Health Organization.

Yermi. 2018. Knowledge and attitudes with Family Role In Prevention of Pulmonary Tuberculosis In Maros. Indonesia. Journal Of Physics 